\title{
Scale Dependence of the Mechanical Properties and Microstructure of Crustaceans Thin Films as Biomimetic Materials
}

\author{
DEVENDRA VERMA, ${ }^{1}$ TAO QU, ${ }^{1}$ and VIKAS TOMAR ${ }^{1,2}$ \\ 1.-School of Aeronautics and Astronautics, Purdue University, West Lafayette, IN 47907, USA. \\ 2.-e-mail: tomar@purdue.edu
}

The exoskeletons of crustacean species in the form of thin films have been investigated by several researchers to better understand the role played by the exoskeletal structure in affecting the functioning of species such as shrimps, crabs, and lobsters. These species exhibit similar designs in their exoskeleton microstructure, such as a Bouligand pattern (twisted plywood structure), layers of different thickness across cross section, change in mineral content through the layers, etc. Different parts of crustaceans exhibit a significant variation in mechanical properties based on the variation in the above-mentioned parameters. This change in mechanical properties has been analyzed by using imaging techniques such as scanning electron microscopy and energy-dispersive x-ray spectroscopy, and by using mechanical characterization techniques such as nanoindentation and atomic force microscopy. In this article, the design principles of these biological composites are discussed based on two shrimp species: Rimicaris exoculata and Pandalus platyceros.

\section{INTRODUCTION}

Natural materials that have developed through millions of years have a hierarchical assembly of its constituent materials. Such assembly provides them exceptional strength, toughness, and stiffness compared with their counterparts. ${ }^{1-9}$ Most recent studies on natural material includes shrimp exoskeleton, ${ }^{3,4}$ crab exoskeletons, ${ }^{10-13}$ lobsters,${ }^{1,2,14,15}$ ganoid scale of an ancient fish, ${ }^{16}$ toucan beak, ${ }^{17,18}$ and sea shells such as nacre and mollusk. ${ }^{19-28}$ These studies have revealed interesting features in the design of such biocomposites that makes them much stronger than the constitutive materials. The exoskeleton of crustaceans such as shrimps, lobsters, and crabs is in the form of multiple thin films stacked in a Bouligand pattern with a well-defined hierarchical structure. ${ }^{1,10,12-15,26,29}$ It consists of chitin-based fibrils coated in proteins at the nanometer level. Such fibrils bind together to form fibers. These fibers are then woven together to form chitin-protein thin-film layers. These layers are stacked in a twisted plywood structure known as the Bouligand pattern.,10,12-15,26,29 The spacing between such woven layers is filled with proteins and biominerals. Studies by Seki et al. ${ }^{17,18}$ have concentrated on a similar kind of exoskeleton found in the beak of toucan. It was found to be a sandwich structure with the exterior of keratin and a closed cell fibrous network made of calcium rich proteins. Raabe et al. ${ }^{1,14}$ have studied the structure and mechanical properties of lobster and crab exoskeletons. They reported that hardness and reduced stiffness change with the depth of examination in the exoskeleton of lobster. The exoskeleton features a graded design with different stacking density of chitin-based Bouligand structure. Boßelmann et al. ${ }^{15}$ have shown a direct correlation between the increase in mineral content and the hardness of lobster claws. Chen et al. ${ }^{10}$ compared the mechanical properties of the crab shell in dry and wet conditions. Exocuticle was found to be more dense and harder than endocuticle; the presence of water leads to increased toughness. Melnick et al. ${ }^{30}$ investigated the effect of dark pigment of stone crab claws on its mechanical properties. Lian and Wang ${ }^{11}$ reported the mechanical properties of dungeon crab exoskeleton. Our previous experimental work on shrimp exoskeletons has been focused on understanding the temperature effect. ${ }^{3,4}$ Studies 
focusing on biomimetic materials include the development of biomimetic scaffolds for tissue growth and fabrication of tissues from biocompatible, biodegradable polymers; ${ }^{31,32}$ the development of the honeycomb plates with design from beetle forewings to eliminate problems of edge sealing and molding process by thoroughly investigating the beetle forewing to be able to mimic its design for better sandwich panel structures; ${ }^{33-36}$ and the development of high-performance functional nanocomposites from graphene sheets with enhanced thermal conductivity and mechanical stiffness. ${ }^{37,38}$

Many mechanistic studies have been performed to study the influence of biological microstructures on biomaterial strength. Feng et al. ${ }^{25}$ found that the crack deflection, fiber pullout, and organic matrix bridging are the three main toughening mechanisms acting on nacre. It was found that the organic matrix also plays an important role in the toughening of this biological composite. This principle that structure and property affect the synthesis of structural ceramic materials can be applied to improve the toughness of ceramics. ${ }^{25}$ Chen et al. ${ }^{22}$ investigated the structure of the natural ceramic mollusk shell for fracture strength and fracture toughness. It has different shapes and arrangements of laminated aragonites and organic layers. The arrangements of aragonites have also various forms, which include parallel, crossed, and inclined. The size, shape, and arrangement adopted depend strongly on the state of local stress. ${ }^{22} \mathrm{Ji}$ and $\mathrm{Gao}^{21}$ showed that the aspect ratio and the staggered alignment of mineral crystals are the key factors contributing to the high stiffness of biocomposites despite the extremely soft protein constituent. The mineral aspect ratio should have an optimum value to balance the stiffness, the strength of mineral crystals, the strength of protein, the strength of interface, the fracture energy, and the viscoelastic properties of biocomposites. ${ }^{21}$ Bechtle et al. $^{7}$ developed models that are capable of predicting the strength values for real biomaterials up to five hierarchical levels by extracting information about the mechanical properties at different hierarchical levels from these experimental data. Mayer ${ }^{8}$ studied the mechanisms underlying the toughening in rigid natural composites exhibited by the concentric cylindrical composites of spicules of sponges, and by the nacre (brick-and-mortar) structure of mollusks. Kumar et al. performed structural characterization studies to understand the construction of the exoskeleton of barnacles. ${ }^{28}$

In this article, the basic design principles of the crustaceans and deformation mechanisms responsible for higher strength, stiffness, toughness are highlighted at different hierarchical levels based on the information obtained by using imaging techniques such as scanning electron microscopy (SEM) as energy-dispersive x-ray spectroscopy (EDX), as well as by using mechanical characterization techniques such as

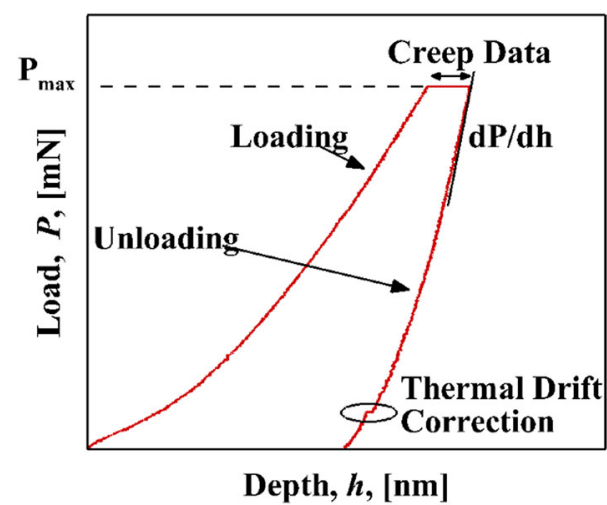

Fig. 1. Indentation curve showing parts of curve used for stiffness, creep, and thermal drift calculations.

nanoindentation and atomic force microscopy (AFM) using example of two shrimp species Rimicaris exoculata and Pandalus platyceros.

\section{METHODS}

Nanoindentation is a preferred method for characterization of the mechanical properties of materials at the microscale and nanoscale. The material being investigated (shrimp exoskeleton) is very thin and heterogeneous. In this material, the traditional uniaxial mechanical loading tests will only provide overall mechanical information, whereas nanoindentation has the capability to give site specific data with minimal sample preparation. This makes nanoindentation a convenient experimental technique to measure elastic modulus and hardness at the nanoscale and microscale.

\section{Nanoindentation}

Figure 1 shows a standard indentation curve and parts of curve used for material property calculations. The experimental procedure involves indenting the surface of material being tested by increasing force in small steps until peak load $\left(P_{\max }\right)$ or peak depth $\left(h_{\max }\right)$ is achieved. The Berkovich indenter was used in the current work. The unloading part was used for predicting the material properties using a framework based on contact mechanics. ${ }^{39,40}$ During the experiments, the maximum indentation load $P_{\max }$ and maximum area of indentation $A$ is measured. The hardness $H$ is given by

$$
H=\frac{P_{\max }}{A}
$$

The parameter $A$ for an ideal Berkovich indenter used in the current work as a function of contact depth $h_{\mathrm{c}}$ is given as

$$
A=3 \sqrt{3} h_{c}^{2} \tan ^{2} 65.3^{\circ} \approx 24.5 h_{c}^{2} .
$$


The reduced Young's modulus $E_{\mathrm{r}}$ is related to the slope of the upper part of the unloading curve by

$$
S=\frac{\mathrm{d} P}{\mathrm{~d} h}=1.17 E_{\mathrm{r}} \sqrt{A} .
$$

Here, $S$ is the stiffness measured experimentally from the slope of unloading curve. Based on known $S$ and $A$ values, $E_{r}$ can be calculated. $E_{r}$ can be used to find the true modulus of the material by the relation

$$
\frac{1}{E_{\mathrm{r}}}=\frac{\left(1-v^{2}\right)}{E}+\frac{\left(1-v_{\mathrm{i}}^{2}\right)}{E_{\mathrm{i}}} .
$$

Here, $E$ and $v$ are the Young's modulus and Poisson's ratio of the specimen under test. $E_{\mathrm{i}}$ and $v_{\mathrm{i}}$ are the Young's modulus and Poisson's ratio of the indenter.

\section{Experimental Setup}

The experiments were performed at room temperature in a multimodule mechanical tester (NanoTest, platform 2; Micro Materials Ltd., Wrexham, U.K.), ${ }^{3,4,41}$ shown in Fig. 2. The instrument consists of a vertical pendulum pivoted on a frictionless spring. An indenter is attached to the pendulum that indents sample horizontally. The force on pendulum was applied through magnetic coils, which allows for a very high sensitivity during experiments. The depth of indents during experiments was measured by the capacitor plates located behind the indenter. Before the experiments, calibrations were performed to obtain accurate measurements of load and depth. Depth calibration, load calibration, and frame compliance experiments were performed before conducting actual experiments. The tip radius of the Berkovich indenter was $20 \mathrm{~nm}$.
During indents, the samples were mounted on the stage firmly to avoid any movement during experiments. The indentations were performed on different samples at the chosen surface as shown in Fig. 3. It was ensured that the sample surface is free of defects before mounting the samples. The indentation locations were chosen randomly, and a series of indents at around ten points were performed. The experiments were performed on ten different samples to capture statistical property differences possibly due to biological changes in samples. The experiments were performed at room temperatures $\left(25^{\circ} \mathrm{C}\right)$. The nanoindentation used for the experiments incorporates a feedback mechanism to accurately stabilize the temperature during experiments. It is always a challenge to simulate exactly the same experimental condition while performing experiments for long time intervals. To avoid discrepancies in the collected data, the best approach used by most researchers is to do all experiments using identical experimental setup. In the current experiments, all measurements were performed using the same indenter, mounting technique, and samples at given temperatures. This gives us much more confidence in our data for comparison purposes. For each data point, approximately 50 indentations were performed.

\section{Scanning Electron Microscopy and Energy Dispersive X-Ray Spectroscopy}

The SEM images were obtained by FEI Nova nanoSEM (FEI Company, Hillsboro, OR). All samples were coated with a platinum layer of $10 \mathrm{~nm}$. It is important to coat biosamples with a metallic layer to discharge the accumulated charge from the surface of sample and to have a clear image. The working distance for Nova SEM was $5 \mathrm{~mm}$ with $5.00 \mathrm{kV}$ accelerating voltage in a high vacuum chamber. EDX analysis was performed using FEI Quanta 3D field-emission gun dual-beam SEM. It is difficult to obtain enough counts per second for the
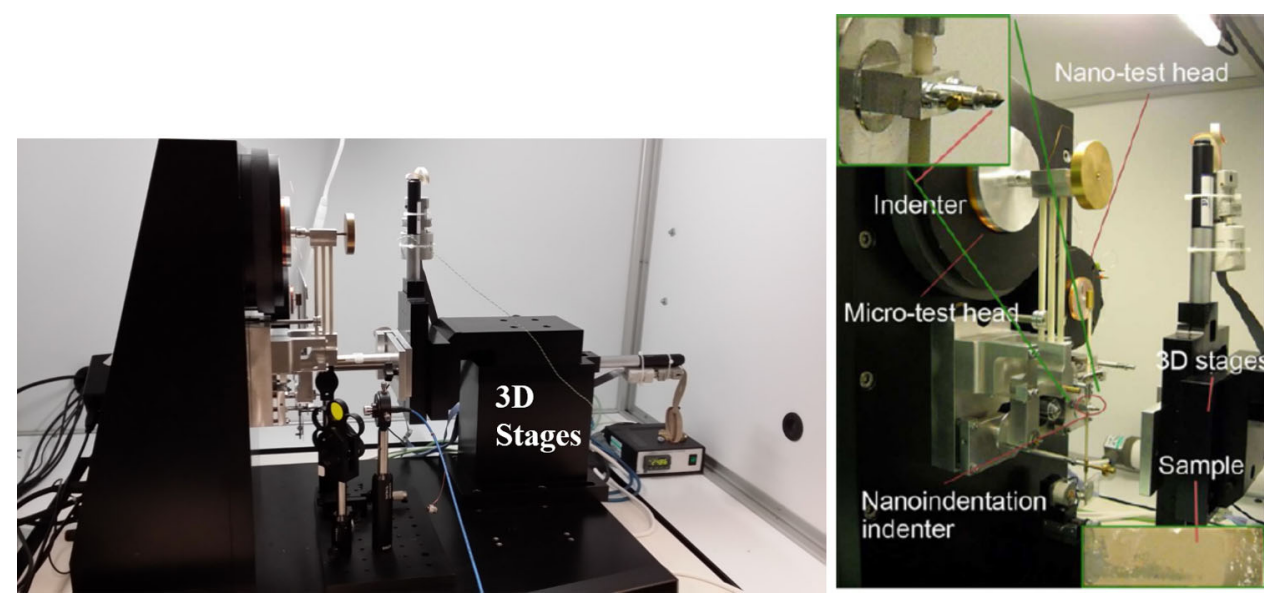

Fig. 2. Instrument setup, NanoTest, Micro Materials Ltd. 
biological samples while performing an elemental analysis at the normal settings used for metals. Therefore, SEM aperture was increased to get higher counts per second to collect the elemental spectrum. The working distance for Quanta SEM was $10 \mathrm{~mm}$ with $20.00 \mathrm{kV}$ accelerating voltage in high vacuum chamber and cryogenic environment. (a)

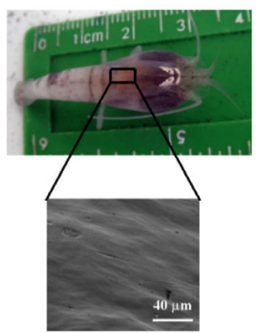

(b)

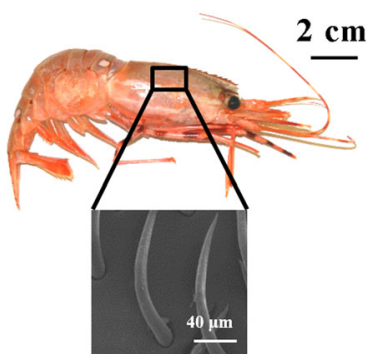

Fig. 3. Analyzed samples of (a) Rimicaris exoculata and (b) Pandalus platyceros.

\section{Sample Preparation}

The samples of $R$. exoculata shrimps were provided by Dr. Juliette Ravaux from the mission Momardream in 2007 from a depth of $2300 \mathrm{~m}$. The shrimps were maintained for $10 \mathrm{~h}$ at $10^{\circ} \mathrm{C}$ with $1 \mathrm{~h}$ heat shock at $30^{\circ} \mathrm{C}$ in pressurized aquaria on board. These shrimp samples were further stored in liquid nitrogen in our laboratory. The $P$. platyceros shrimps were obtained in fresh unfrozen conditions to prepare the samples. The shrimps were immediately stored in frozen conditions after procurement. The samples for mechanical testing were prepared from these shrimps specimens. Figure 3 shows whole shrimps and prepared samples for $R$. exoculata and P. platyceros. To prepare the samples, the shrimps were taken out and carapace was removed carefully without mechanically straining or producing any fracture in it. The samples were cut from carapace. Carapace is the exoskeleton of the shrimp that protects the cephalothoracic region of the shrimp. Cephalothoracic is the front part of the shrimp that contains vital parts of shrimp
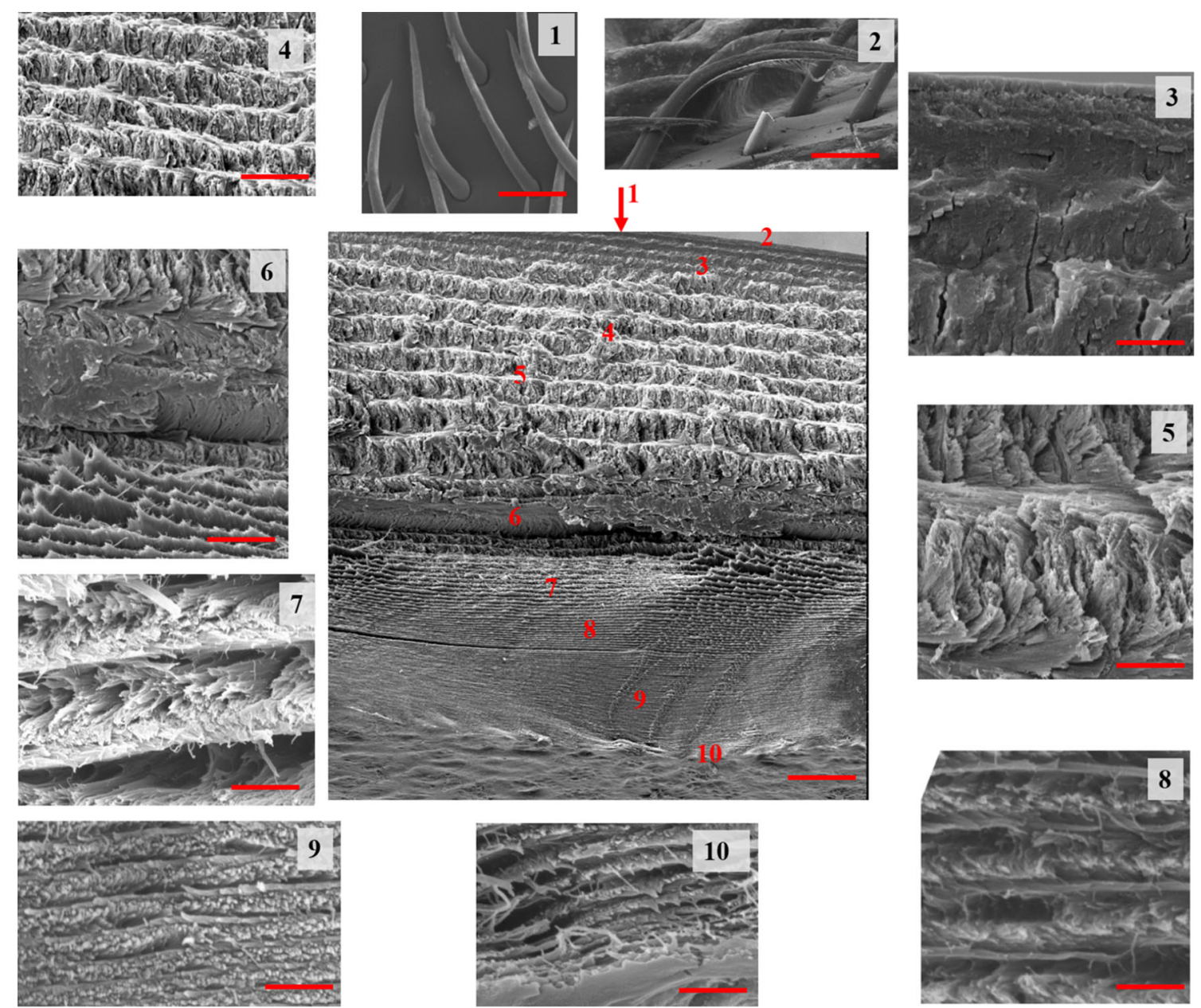

Fig. 4. Full cross section in the middle and zoomed sections of the cross section labeled from 1 to 10 around it for Pandalus platyceros. Scale bars: Full cross section-20 $\mu \mathrm{m}$, (1) $100 \mu \mathrm{m}$, (2) $50 \mu \mathrm{m}$, (3) $2 \mu \mathrm{m}$, (4) $10 \mu \mathrm{m}$, (5) $3 \mu \mathrm{m}$, (6) $5 \mu \mathrm{m}$, (7) $1 \mu \mathrm{m}$, (8) $500 \mathrm{~nm}$, (9) $500 \mathrm{~nm}$, and (10) $500 \mathrm{~nm}$. 

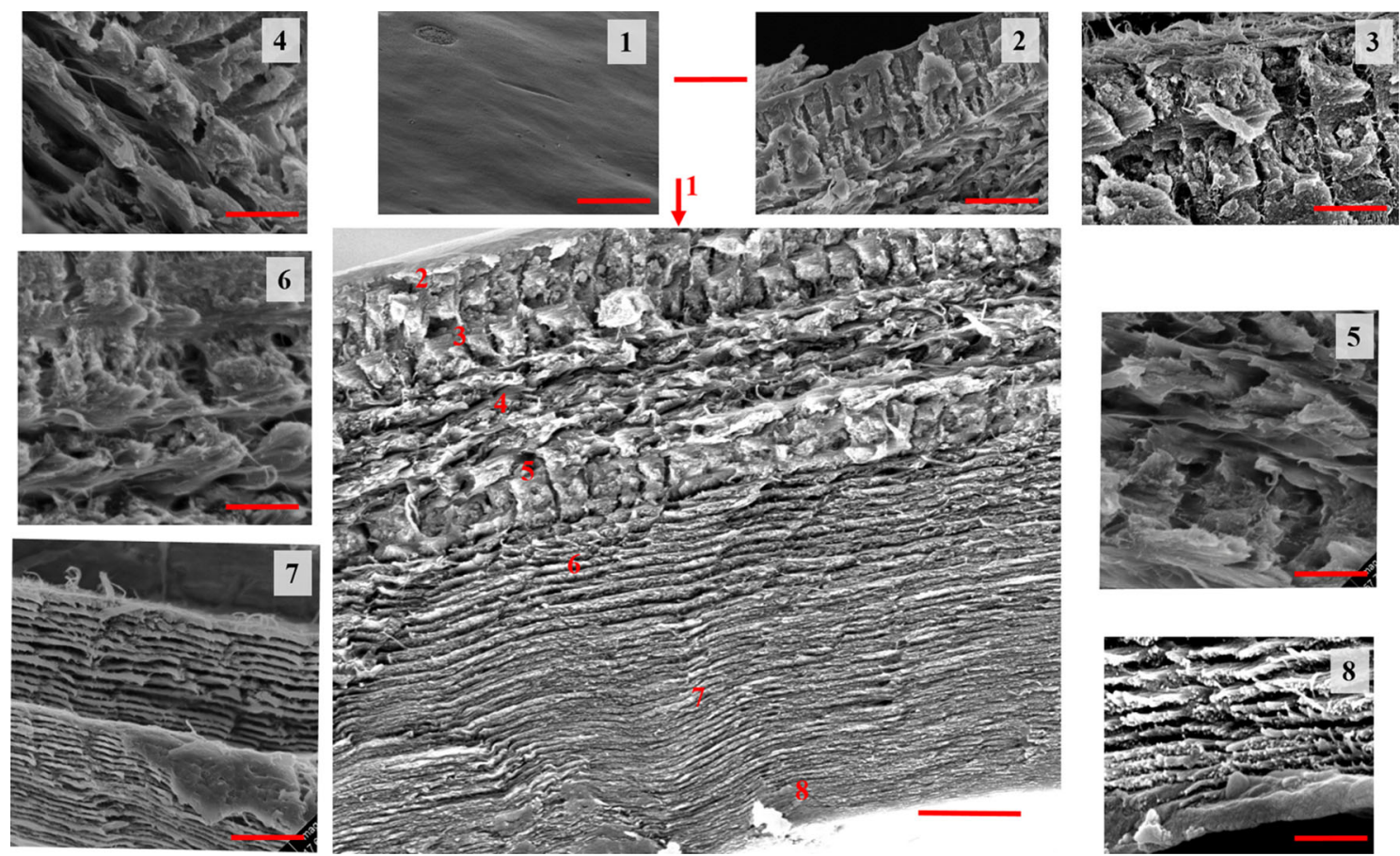

Fig. 5. Full cross section in the middle and zoomed sections of the cross section labeled from 1 to 8 around it for Rimicaris exoculata. Scale bars: Full cross section-5 $4 \mathrm{~m}$, (1) $20 \mu \mathrm{m}$, (2) $2 \mu \mathrm{m}$, (3) $1 \mu \mathrm{m}$, (4) $1 \mu \mathrm{m}$, (5) $1 \mu \mathrm{m}$, (6) $1 \mu \mathrm{m}$, (7) $2 \mu \mathrm{m}$, and (8) $500 \mathrm{~nm}$.

including mouth, eyes, antennas, etc. Carapace will be referred to as shrimp exoskeleton further in this article. The shrimp exoskeletons were then dried in open air for 3 days to prepare the samples for indentation tests.

\section{Substrate Effects}

Substrate could play a major role in the measurement of reduced modulus values of thin samples. The general rule is that the indentation depth should be less than $10 \%$ of the total thickness of sample. ${ }^{42-44}$ The thickness of $R$. exoculata samples was $20 \pm 1 \mu \mathrm{m}$ and the indentation depth was $300 \mathrm{~nm}$. The thickness of the P. platyceros samples was $110 \pm 10 \mu \mathrm{m}$ and the indentation depth was $1 \mu \mathrm{m}$, which satisfies the $10 \%$ rule. This verifies that substrate effect has been taken into account during indentations.

\section{RESULTS}

Two different shrimp species, $R$. exoculata and $P$. platyceros, were analyzed in the current study. The reduced modulus and hardness were measured by nanoindentation. There was a clear difference in the reduced modulus and hardness properties, which occurs because of the difference in the design of the shrimp exoskeleton. As shown in Figs. 4 and 5, there is a clear nonuniformity in the stacking density and thickness of layers across the cross section. The figures show the inner side of the exoskeleton at the bottom of figure and the outer side of the exoskeleton at the top of the figure. Each visible layer is a layer of woven $\alpha$-chitin-protein fiber network, which is the characteristic feature of exoskeleton of crustaceans. ${ }^{1,14,15}$ It consists of different kinds of proteins and minerals. Both shrimp exoskeletons does have the similar features such as the Bouligand structure, and the layered structure with thicker layers on the top and thinner layers at the bottom that can be visualized from Figs. 4 and 5 . There is a difference in the length scale, however. $P$. platyceros in Fig. 4 shows thicker layers and overall higher thickness than the $R$. exoculata shown in Fig. 5. Figure 4 also shows zoomed-in images from different parts of the cross section of $P$. platyceros labeled from 1 to 10 on the full cross section. The surface of the exoskeleton shows hairy features, Fig. 4(1 and 2). The topmost layers are more closely knit together, making them a fairly homogeneous structure, Fig. 4(3). Different layers just below the top surface are visible, Fig. 4(4). A close-up image on a layer shows the Bouligand pattern, Fig. 4(5). The layers in this region of the shrimp are thicker than the lower part. As we go down and around middle section, the thickness of the layers changes to almost half of the original thickness, Fig. 4(6). After this point, the layer thickness keeps on decreasing, Fig. 4(7-9) with the minimum thickness layers at the bottom, Fig. 4(10) of the cross section of the exoskeleton.

Similarly, Fig. 5 shows zoomed-in images from different parts of the cross section of $R$. exoculata labeled from 1 to 8 on the full cross section. The surface of the exoskeleton shows no hairs, Fig. 5(1). The topmost layers, Fig. 5(2) are not as 

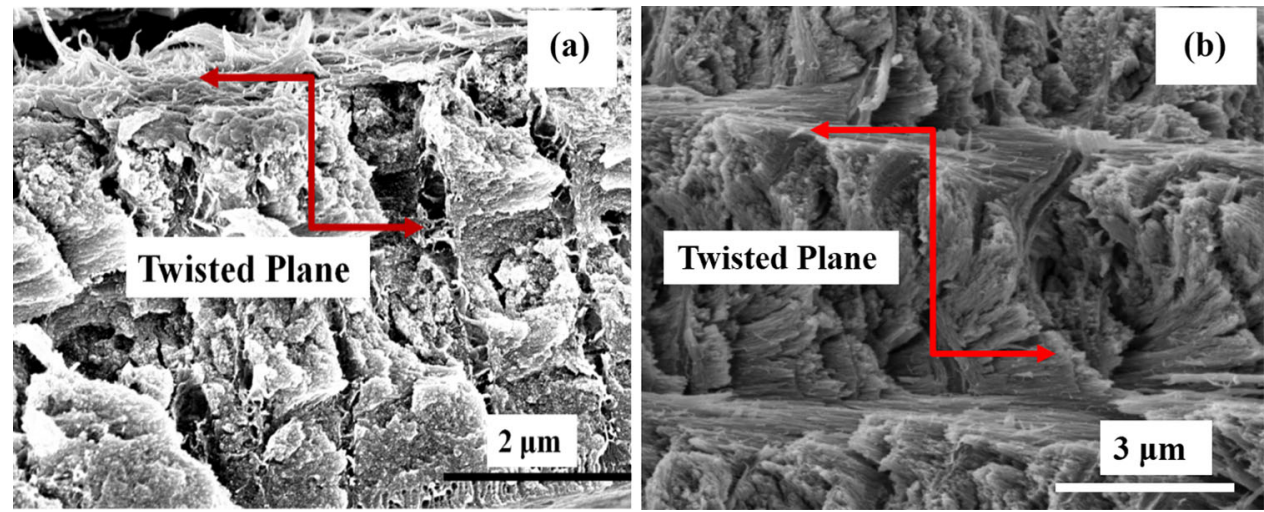

Fig. 6. Bouligand structure of shrimp exoskeleton (a) Rimicaris exoculata and (b) Pandalus platyceros.
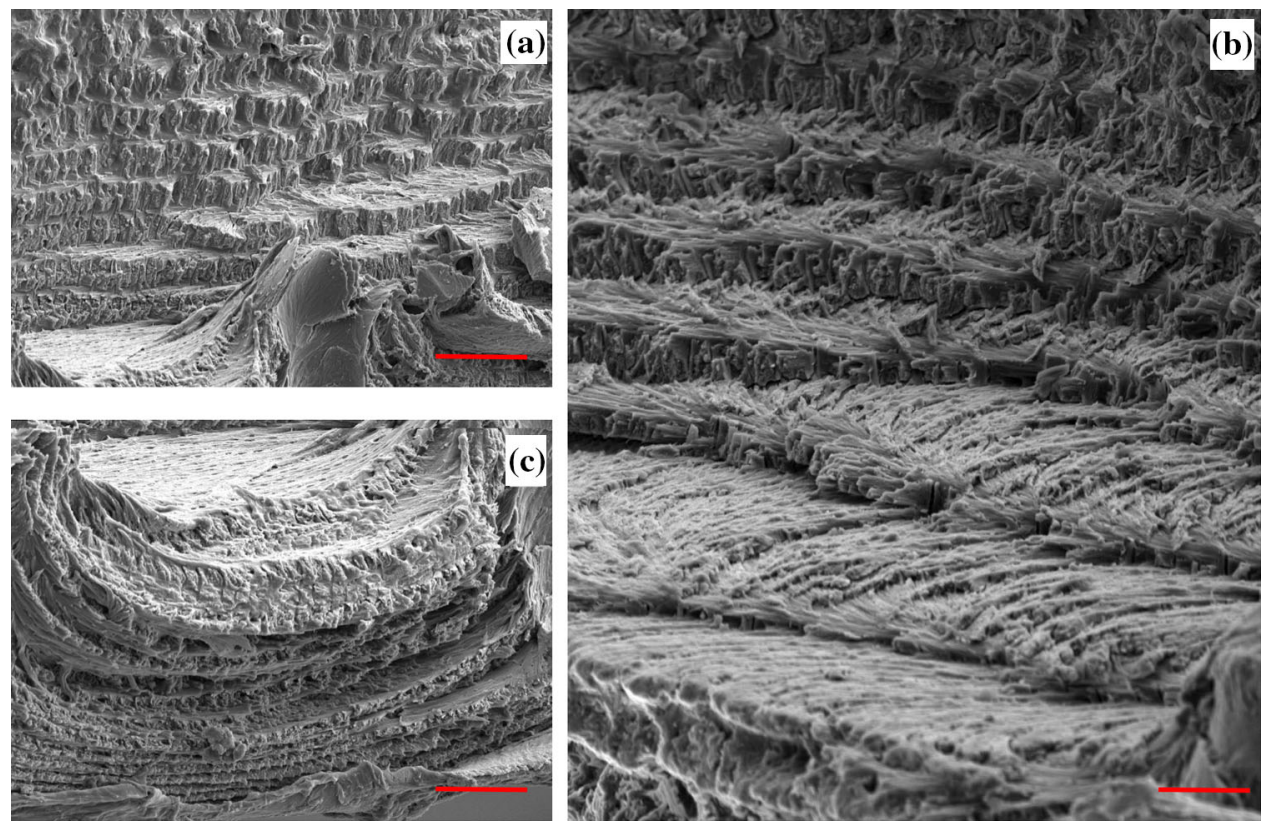

Fig. 7. Images showing failures and fractures in the cross section of Pandalus platyceros (a) in top layer, (b) delamination, and (c) bending of layers around hairs. Scale bars: (a) $15 \mu \mathrm{m}$, (b) $6 \mu \mathrm{m}$, and (c) $10 \mu \mathrm{m}$.

homogeneous as we observed in Fig. 4. Different layers just below the top surface are visible in Fig. 5(3 and 4). A close-up image on a layer shows the Bouligand pattern Fig. 5(3). The layers in this region of the shrimp are thicker than the lower part. The thickness of the layers is not changing into a uniform fashion, however. The topmost layers are thicker, Fig. 5(2 and 3), following layers of lower thickness, Fig. 5(4) that further increase in thickness, Fig. 5(5) until the half of total thickness of cross section is reached. As we go down, we observe around the middle section that the thickness of layers changes again to much thinner layers, Fig. 5(6). After this point, the layer thickness keeps on decreasing, Fig. 5(7), with the minimum thickness layers at the bottom, Fig. 5(8) of the cross section of the exoskeleton.
The maximum thickness of a layer in the $P$. platyceros is $2 \mu \mathrm{m}$ as opposed to $1 \mu \mathrm{m}$ in the $R$. exoculata exoskeleton. $R$. exoculata shows a nonuniform change of the thickness of the layers as compared with $P$. platyceros. The minimum thickness at bottom most regions is in the range of 20-30 nm for $R$. exoculata, whereas in P. platyceros it is in the range of 50-100 $\mathrm{nm}$. The similarity in the individual layers of both shrimps can be exhibited from the Bouligand pattern as shown in Fig. 6 .

Further analysis of the SEM images shows the failure patterns in both species exoskeletons. Figure 7(1) shows the layers of cross section in the $P$. platyceros upper section with the bend layers in Fig. 7(3). A closer picture showing the delamination of layers is shown in Fig. 7(2). It shows the crosslinked pattern between the two layers at the edges 

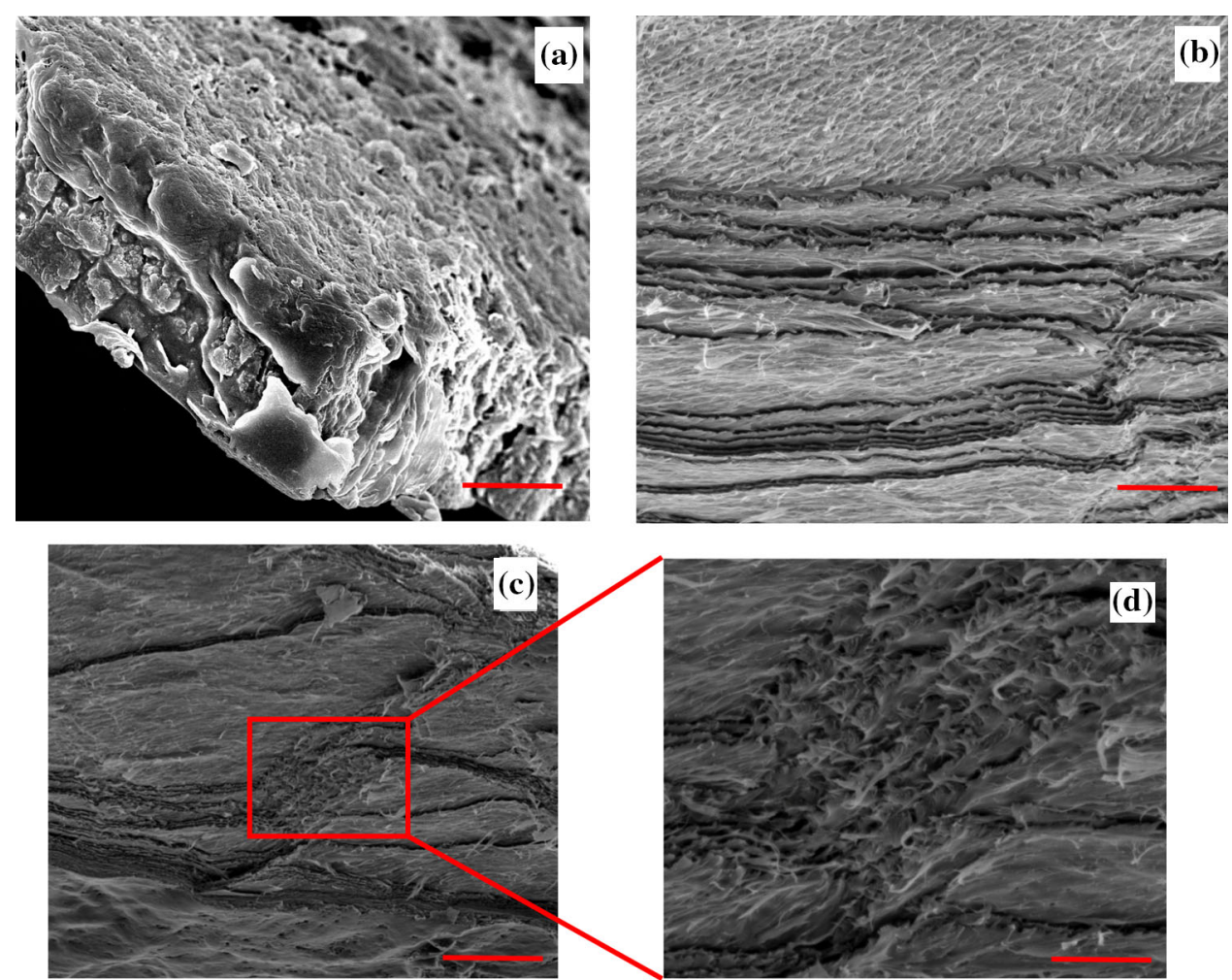

Fig. 8. Images showing failures and fractures in the cross section of Pandalus platyceros: (a) delaminated layer, (b) interlayer delamination, (c) fracture in the layers, and (d) zoomed image of fiber pullout from fracture in layers. Scale bars: (a) $3 \mu \mathrm{m}$, (b) $5 \mu \mathrm{m}$, (c) $10 \mu \mathrm{m}$, and (d) $3 \mu \mathrm{m}$.

Table I. Comparison of quantitative data by EDX analysis on cross section of shrimp exoskeleton for Rimicaris exoculata and Pandalus platyceros

\begin{tabular}{|c|c|c|}
\hline Element & $\begin{array}{c}\text { Rimicaris } \\
\text { exoculata (at.\%) }\end{array}$ & $\begin{array}{c}\text { Pandalus } \\
\text { platyceros (at.\%) }\end{array}$ \\
\hline $\mathrm{C}$ & $42.89 \pm 0.97$ & $46.20 \pm 1.19$ \\
\hline $\mathrm{O}$ & $27.76 \pm 1.89$ & $42.41 \pm 1.79$ \\
\hline $\mathrm{P}$ & $3.14 \pm 1.12$ & - \\
\hline $\mathrm{Ca}$ & $26.2 \pm 1.73$ & $9.86 \pm 2.20$ \\
\hline
\end{tabular}

of the two layers. These interconnected layers enhance the flexibility and robustness of these exoskeletons. Similar delamination in the $R$. exoculata exoskeleton can be seen from, Fig. 8(1 and 2 ). In this exoskeleton, the individual layers are more closely packed. The layers are much thinner with the fracture of layers accompanied by fiber out, Fig. 4(3 and 4). These layers shows bending at even smaller length scales, Fig. 8(2).

In addition to the difference in the structure, these species also show differences in the chemical composition of the exoskeleton. The chemical composition at the top layers at the sites of indention was compared by taking EDX spectrums. Both spectrum were collected using same QUANTA 3D SEM at Purdue University. The elemental composition calculated from the spectrums is given in Table I.
Table II. Reduced modulus and hardness of shrimp exoskeleton for Rimicaris exoculata and Pandalus platyceros

\begin{tabular}{lccc}
\hline Property & $\begin{array}{l}\text { Rimicaris } \\
\text { exoculata }\end{array}$ & $\begin{array}{c}\text { Pandalus } \\
\text { platyceros }\end{array}$ \\
\cline { 1 - 1 } Reduced modulus & & $8.27 \pm 0.89$ & \\
Hardness & $0.31 \pm 0.07$ & & $1.52 \pm 0.38 \pm 2.3$ \\
\hline
\end{tabular}

This result is comparable with the chemical composition obtained by several researchers on coastal shrimps. ${ }^{45-51} R$. exoculata shows some variations in composition with noticeable phosphorus. Table I gives a relative quantitative analysis of the individual elements present in the exoskeleton of both shrimps. The presence of Ca supports the fact that $R$. exoculata survives at very high pressures and needs to have more structural strength to survive. Phosphorus is one of the materials from volcanic vents in nearby habitat of $R$. exoculata. It also became part of the shrimp exoskeleton with the evolution of shrimps near deep sea vents possibly via food sources. A combination of observations from Figs. 4, 5, 6, 7, 8 and Table I reveals that the Rimicaris exoskeleton has a higher content of mineral and reduced protein layer thicknesses than $P$. platyceros. The reduced modulus and hardness of both species is given in Table II. The difference in these properties can be attributed to the changes at 
Table III. Creep compliance fitting parameters from Eq. 5 on experimental dwell data

\begin{tabular}{|c|c|c|c|}
\hline Species & $C_{0}\left(\mathbf{P a}^{-1}\right)$ & $C_{1}\left(\mathrm{~Pa}^{-1}\right)$ & $\tau_{1}(\mathbf{s})$ \\
\hline $\begin{array}{l}\text { Rimicaris exoculata } \\
\text { Pandalus platyceros }\end{array}$ & $\begin{array}{l}1.45 \mathrm{e}-6 \pm 8.21 \mathrm{e}-8 \\
1.08 \mathrm{e}-6 \pm 8.16 \mathrm{e}-8\end{array}$ & $\begin{array}{l}4.60 \mathrm{e}-7 \pm 4.97 \mathrm{e}-9 \\
1.38 \mathrm{e}-7 \pm 4.80 \mathrm{e}-9\end{array}$ & $\begin{array}{l}86.33 \pm 1.24 \\
68.00 \pm 1.63\end{array}$ \\
\hline
\end{tabular}

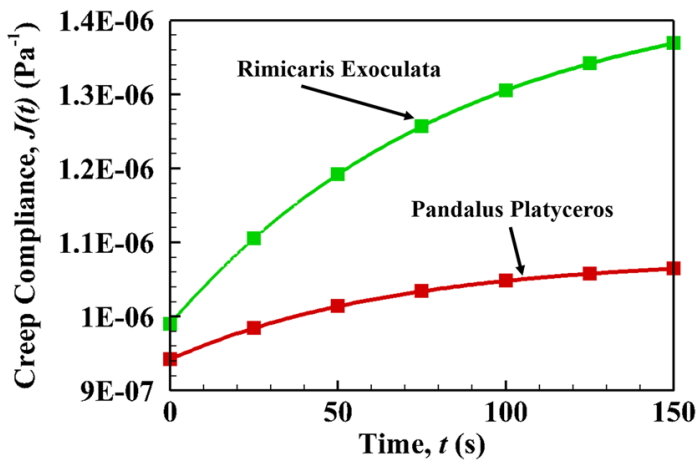

Fig. 9. Creep compliance functions $J(t)$ for Rimicaris exoculata and Pandalus platyceros from Eq. 6.

the structural and chemical composition as mentioned in the previous discussion. Figure 4(3) shows the closely packed layers in $P$. platyceros at the top, whereas Fig. 5(2) indicates that the layers on the top of $R$. exoculata show some porosity. This is also one reason for the reduced mechanical properties.

Further analysis was performed on the creep data obtained from the nanoindentation experiments. A hold period was applied at the maximum load to collect dwell data. The hardness of a material is its ability to resist deformation under applied stress. In the current material, creep compliance follows the trend of hardness. There are several formulations to fit the nanoindentation creep given by Oyen et al. ${ }^{52-54}$ and $\mathrm{Lu}$ et al. $^{55}$ The model chosen in the current article is the best fit for the nanoindentation data of the creep. It uses the dwell data over time for the holding period to calculate creep compliance parameters. To model the load-deformation behavior exhibited by examined shrimp exoskeletons, the creep data are fitted with the creep function given for viscoelastic materials by Oyen ${ }^{52}$ as

$h^{2}=\frac{\gamma^{2}}{\pi \tan \psi}\left\{C_{0} k t_{R}-\sum C_{i} k \tau_{i} \exp \left(\frac{-t}{\tau_{i}}\right)\left[\exp \left(\frac{t_{R}}{\tau_{i}}\right)-1\right]\right\}$

where $h$ is the indentation depth during the dwell period, $\psi$ is the indenter included angle, $\gamma$ is a constant relating contact displacement to total displacement, $k$ is the loading rate, $t_{R}$ is the start time of dwell period, $C_{i}$ and $\tau_{i}$ are the creep compliance coefficients, and $t$ is the time period of loading. One term approximation of Eq. 5 is fitted to the experimental creep data to find coefficients $C_{i}$ and $\tau_{i}$. The respective coefficients for both $R$. exoculata and $P$. platyceros are tabulated in Table III.
The creep compliance parameters obtained from Eq. 5 were then used to plot the creep compliance given in Fig. 9 from Eq. 6,

$$
J(t)=C_{0}-\sum_{i=1}^{j} C_{i} \exp \left(\frac{-t}{\tau_{i}}\right)
$$

where $C_{i}$ and $\tau_{i}$ are creep compliance coefficients, and $t$ the is time period of loading. As shown in Fig. 9, the creep compliance for $R$. exoculata is higher than $P$. platyceros because of the lower hardness of $R$. exoculata exoskeleton. The basic building blocks of the $R$. exoculata and the $P$. platyceros exoskeleton are polymer chains made up of chitin proteins and calcium-based biominerals. The matrix material is made up of chitin-protein fibers woven together in a planar structure. The spacing between woven fibers is filled with biominerals, mostly of $\mathrm{CaCO}_{3}$. These layers are then arranged to form a twisted plywood structure known as Bouligand pattern. ${ }^{1,14}$ Such hierarchy in this structure makes it similar to polymer composites. The creep compliance functions fit nicely to the creep data of the shrimp exoskeletons.

The other reasons for the changes in structure that leads to changes in the mechanical properties can be found in the habitat of both species. The $R$. exoculata lives at high temperature and pressure at depths of $2300 \mathrm{~m}$ and near high temperature deep sea vents ${ }^{56-60}\left(\sim 500^{\circ} \mathrm{C}\right)$. $P$. platyceros lives at sea level and does not need to sustain high pressures and temperatures. $R$. exoculata has a higher mineral content for toughness but maintains porosity in the structural design to keep its structure flexible. At sea level, $P$. platyceros needs to encounter several animals that are above it in the food chain, so it needs to maintain higher structural strength, thus having higher modulus and hardness. These two species provide a good example that exhibits changes in its microstructure to develop its exoskeleton according to the requirements of their habitats.

\section{CONCLUSION}

A series of experiments were performed at room temperature on the exoskeletons of $R$. exoculata and $P$. platyceros to understand structure-dependent mechanical strength. The structures were also studied extensively by using the SEM and EDX analyses. A comparison is drawn between the properties of the exoskeletons of $R$. exoculata and $P$. platyceros based on their microstructure and chemical compositions. The differences in the reduced 
modulus and hardness for both shrimp species are attributed to their habitat and subsequent changes in the microstructural design, such as changes in the individual layer thicknesses, pattern of layer thicknesses, and chemical composition. The results are also fitted with viscoelastic creep compliance functions, which further shows Rimicaris to have higher creep than $P$. platyceros due to its lower hardness.

\section{ACKNOWLEDGEMENTS}

The authors express their sincere thanks to Dr. Juliette Ravaux, Université Pierre et Marie Curie for providing samples of $R$. exoculata. Also, the authors would like to acknowledge the excellent technical assistance of Dr. Christopher J. Gilpin, Chia-Ping Huang, and Laurie Mueller with SEM and EDX at Purdue University. Last, I would like to thank my colleagues Dr. Devendra Dubey, Dr. Ming Gan, Dr. You Sung Han, and Dr. Hongsuk Lee for helpful discussions. This research was funded by NSF CMMI Biomechanics and Mechanobiology program (CMMI 1131112).

\section{REFERENCES}

1. D. Raabe, C. Sachs, and P. Romano, Acta Mater. 53(15), 4281 (2005).

2. S. Nikolov, M. Petrov, L. Lymperakis, M. Friák, C. Sachs, H.-O. Fabritius, D. Raabe, and J. Neugebauer, Adv. Mater. 22(4), 519 (2010).

3. D. Verma and V. Tomar, J. Bionic Eng. 11(3), 360 (2014).

4. D. Verma and V. Tomar, Mater. Sci. Eng. C 44, 371 (2014).

5. F. Bouville, E. Maire, S. Meille, B. Van de Moortèle, A.J. Stevenson, and S. Deville, Nat. Mater. 13(5), 508 (2014).

6. J.-Y. Sun and J. Tong, J. Bionic Eng. 4(1), 11 (2007).

7. S. Bechtle, S.F. Ang, and G.A. Schneider, Biomaterials 31(25), 6378 (2010).

8. G. Mayer, J. Mechan. Behavior. Biomed. Mater. 4(5), 670 (2011).

9. M.S. Wu, Mater. Sci. Eng. C 31(6), 1209 (2011).

10. P.-Y. Chen, A.Y.-M. Lin, J. McKittrick, and M.A. Meyers, Acta Biomater. 4(3), 587 (2008).

11. J. Lian and J. Wang, Mechanics of Biological Systems and Materials, Vol. 2, ed. T. Proulx (New York: Springer, 2011), p. 93.

12. H.R. Hepburn, I. Joffe, N. Green, and K.J. Nelson, Comp. Biochem. Physiol. Part A 50(3), 551 (1975).

13. M.M. Giraud-Guille, Tissue Cell 16(1), 75 (1984).

14. D. Raabe, P. Romano, C. Sachs, H. Fabritius, A. Al-Sawalmih, S.-B. Yi, G. Servos, and H. Hartwig, Mater. Sci. Eng. A 421(1), 143 (2006).

15. F. Boßelmann, P. Romano, H. Fabritius, D. Raabe, and M. Epple, Thermochim. Acta 463(1-2), 65 (2007).

16. L. Wang, J. Song, C. Ortiz, and M.C. Boyce, J. Mater. Res. 24(12), 3477 (2009).

17. Y. Seki, M.S. Schneider, and M.A. Meyers, Acta Mater. 53(20), 5281 (2005).

18. Y. Seki, B. Kad, D. Benson, and M.A. Meyers, Mater. Sci. Eng. C 26(8), 1412 (2006).

19. G. Mayer, Mater. Sci. Eng. C 26(8), 1261 (2006).

20. X. Li and P. Nardi, Nanotechnology 15(1), 211 (2004).

21. B. Ji, H. Gao, and J. Mechan, Phys. Solids 52(9), 1963 (2004).

22. B. Chen, X. Peng, J.G. Wang, and X. Wu, Ceram. Int. 30(7), 2011 (2004).

23. H. Gao, B. Ji, I.L. Jäger, E. Arzt, and P. Fratzl, Proc. Natl. Acad. Sci. USA 100(10), 5597 (2003).

24. C.-A. Wang, Y. Huang, Q. Zan, H. Guo, and S. Cai, Mater. Sci. Eng. C 11(1), 9 (2000).
25. Q.L. Feng, F.Z. Cui, G. Pu, R.Z. Wang, and H.D. Li, Mater. Sci. Eng. C 11(1), 19 (2000).

26. F. Barthelat, J.E. Rim, and H.D. Espinosa, Applied Scanning Probe Methods XIII (New York: Springer, 2009), p. 17.

27. G.M. Luz and J.F. Mano, Philos. Trans. R. Soc. A 367(1893), 1587 (2009).

28. S. Raman and R. Kumar, J. Struct. Biol. 176(3), 360 (2011).

29. Y. Bouligand, Tissue Cell 4(2), 189 (1972).

30. C.A. Melnick, Z. Chen, and J.J. Mecholsky, J. Mater. Res. 11(11), 2903 (1996).

31. B.-S. Kim and D.J. Mooney, Trends Biotechnol. 16(5), 224 (1998).

32. H. Shin, S. Jo, and A.G. Mikos, Biomaterials 24(24), 4353 (2003).

33. J. Chen, Q.-Q. Ni, Y. Xu, and M. Iwamoto, Compos. Struct. 79(3), 331 (2007).

34. J. Chen, C. Gu, S. Guo, C. Wan, X. Wang, J. Xie, and X. Hu, Mater. Sci. Eng. C 32(7), 1813 (2012).

35. J. Chen, J. Xie, H. Zhu, S. Guan, G. Wu, M.N. Noori, and S. Guo, Mater. Sci. Eng. C 32(3), 613 (2012).

36. J. Chen and G. Wu, Carbohydr. Polym. 91(2), 659 (2013).

37. S. Stankovich, D.A. Dikin, G.H.B. Dommett, K.M. Kohlhaas, E.J. Zimney, E.A. Stach, R.D. Piner, S.T. Nguyen, and R.S. Ruoff, Nature 442(7100), 282 (2006).

38. T. Ramanathan, A.A. Abdala, S. Stankovich, D.A. Dikin, M. Herrera Alonso, R.D. Piner, D.H. Adamson, H.C. Schniepp, X. Chen, R.S. Ruoff, S.T. Nguyen, I.A. Aksay, R.K. Prud'Homme, and L.C. Brinson, Nat. Nanotechnol. 3(6), 327 (2008).

39. W.C. Oliver and G.M. Pharr, J. Mater. Res. 7(6), 1564 (1992).

40. G. Pharr, Mater. Sci. Eng. A 253(1), 151 (1998).

41. M. Gan and V. Tomar, Mater. Sci. Eng. A 527(29-30), 7615 (2010).

42. R. Saha and W.D. Nix, Acta Mater. 50(1), 23 (2002).

43. C. Gamonpilas and E.P. Busso, Mater. Sci. Eng. A 380(1-2), 52 (2004).

44. D. Kramer, A. Volinsky, N. Moody, and W. Gerberich, J. Mater. Res. 16(11), 3150 (2001).

45. S. Ravichandran, G. Rameshkumar, and A.R. Prince, Am. Eurasian J. Scientif. Res. 4(3), 191 (2009).

46. F. Ehigiator and E. Oterai, Int. J. Res. Rev. Appl. Sci. 11(1), 162 (2012).

47. I.A. Emmanuel, H.O. Adubiaro, and O.J. Awodola, Pak. J. Nutr. 7(6), 741 (2008).

48. R.H. Rødde, A. Einbu, and K.M. Vårum, Carbohydr. Polym. 71(3), 388 (2008)

49. H.M. Ibrahim, M.F. Salama, and H.A. El-Banna, Food/ Nahrung. 43(6), 418 (1999).

50. F. Shahidi, J. Synowiecki, and J. Agricult, Food Chem. 39(8), 1527 (1991).

51. M. Islam, S. Masum, M. Rahman, M. Moll, A. Shaikh, and S. Roy, Int. J. Basic Appl. Sci. 11(1), 116 (2011).

52. M. Oyen, Philos. Mag. 86(33-35), 5625 (2006).

53. M.L. Oyen and R.F. Cook, J. Mater. Res. 18(1), 139 (2003).

54. R.F. Cook and M.L. Oyen, Int. J. Mater. Res. 98(5), 370 (2007)

55. H. Lu, B. Wang, J. Ma, G. Huang, and H. Viswanathan, Mechan. Time Depend. Mater. 7(3-4), 189 (2003).

56. H. Fricke, O. Giere, K. Stetter, G.A. Alfredsson, J.K. Kristjansson, P. Stoffers, and J. Svavarsson, Marine Biol. 102(3), 425 (1989).

57. D. Desbruyères, M. Biscoito, J.C. Caprais, A. Colaço, T. Comtet, P. Crassous, Y. Fouquet, A. Khripounoff, N. Le Bris, K. Olu, R. Riso, P.M. Sarradin, M. Segonzac, and A. Vangriesheim, Deep Sea Res. Part I 48(5), 1325 (2001).

58. S.T. Ahyong, Crustaceana 82(7), 775 (2009).

59. R.C. Vrijenhoek, Molec. Ecol. 19(20), 4391 (2010).

60. D.P. Connelly, J.T. Copley, B.J. Murton, K. Stansfield, P.A Tyler, C.R. German, C.L. Van Dover, D. Amon, M. Furlong, N. Grindlay, N. Hayman, V. Huhnerbach, M. Judge, T. Le Bas, S. McPhail, A. Meier, K.-I. Nakamura, V. Nye, M. Pebody, R.B. Pedersen, S. Plouviez, C. Sands, R.C. Searle, P. Stevenson, S. Taws, and S. Wilcox, Nat. Commun. 3, 620 (2012). 